Fecha de recepción: julio 2020

Fecha de aprobación: octubre 2020

Fecha publicación: enero 2021

\section{LIJ y educación literaria en Argentina: entre políticas públicas y mercado editorial}

Patricia B. Bustamante ${ }^{(1)}$

Resumen: El artículo analiza la presencia material de obras literarias en las escuelas argentinas. Revisa la responsabilidad estatal en la distribución de bienes materiales y simbólicos mediante el análisis de políticas públicas de lectura y provisión de colecciones literarias desarrolladas durante el período 2010-2015, desde la Dirección de Políticas Socioeducativas del Ministerio de Educación de la Nación, y sus posibles efectos sobre el canon literario escolar. Se indaga, particularmente en la presencia de autores y títulos del recorte literatura infantil y juvenil incluidos en las bibliotecas literarias estudiadas.

Palabras clave: Libros - Canon escolar literario - Argentina.

[Resúmenes en inglés y portugués en la página 186]

(1) Profesora en Letras. Magister en Didáctica. Dirige equipos de investigación acerca de lectura, formación de lectores, enseñanza de la lengua y la literatura, literatura juvenil y políticas públicas de lectura. Profesora Asociada a cargo de la cátedra de Didáctica de la Lengua y la Literatura y Profesora Adjunta a cargo de la cátedra de Literatura infantil y juvenil, ambas en la carrera de Letras de la Universidad Nacional de Salta.

\title{
Introducción
}

Pensar la educación literaria nos interpela en varios sentidos: la selección de textos y autores puestos en circulación en el mercado, la constitución del canon, las estrategias didácticas, la formación del lector, entre otras. En estas discusiones, no es menor la cuestión de la presencia material de los textos en las escuelas, en tanto la disponibilidad juega un papel central en los procesos de canonización y en las prácticas de lectura. Por ello, nos interrogamos acerca de cómo podría impactar -en el canon escolar- la disponibilidad material de los textos distribuidos en el marco de las políticas públicas de provisión de libros. Nos preocupa -básicamente- problematizar los criterios de selección con que se incluyen -en las colecciones entregadas a las escuelas argentinas por el Estado nacional- autores y títulos propuestos por el mercado editorial y preguntarnos acerca de la potencialidad de éstos para traccionar del canon escolar. 
Para este estudio acudimos -en un primer momento- a fuentes documentales emanadas del Ministerio de Educación de la Nación y a entrevistas con actores de los procesos de selección y compra de ejemplares de literatura para consolidar la "Colección Literaria para Secundaria". En un segundo momento realizamos análisis literarios de parte del corpus de la Colección.

\section{Políticas públicas educativas y mercado editorial en Argentina}

Como parte de las políticas desplegadas por el Ministerio de Educación de la Nación, la provisión de dotaciones de libros se atendió desde diversos planes y programas, en tanto la lectura se definió como prioridad y las políticas de lectura se comprometían -según los acuerdos de los jefes de estados en la XIII Cumbre Iberoamericana realizada en Santa Cruz de la Sierra, en el año 2003- a garantizar "los mecanismos de financiamiento y organizativos para la disponibilidad de libros y otros materiales de lectura que permitan a la población el acceso a la cultura escrita"1.

Estos acuerdos tienen, obviamente, diversos grados de concreción en el país y pueden ser objeto de distintos enfoques y análisis. En Argentina, en una etapa anterior a este consenso de jefes de Estado, durante el gobierno de recuperación democrática liderado por Raúl Alfonsín, se desarrolló entre 1984 y 1989 el Plan de Lectura dirigido por Hebe Clementi desde la Dirección Nacional del Libro. Con presupuesto limitado, los talleres y libros llegaron a algunas jurisdicciones del país, con la modalidad de valijas y talleristas viajeros. Por otra parte, el Plan Social Educativo, entre 1993 y 1999, distribuyó cajas con títulos que iban desde la literatura infantil y juvenil y su teorización ${ }^{2}$ hasta las didácticas específicas y la pedagogía en las escuelas de todo el país. En el marco de la reforma educativa neoliberal del gobierno menemista, el espectro de títulos enviados para dotar las bibliotecas escolares fue de tal diversidad que no permite encontrar un hilo conductor vinculado con una clara política de estado en relación con la formación de lectores. En los envíos, de cobertura universal tanto para escuelas de gestión pública como privada, se entrecruzan títulos para formación docente, teorías sobre la lectura, literatura infantil y juvenil (LIJ) y didácticas específicas. Evidentes razones de mercado, impulsaron compras masivas de títulos comercializados en la reforma española, muchos de ellos destinados al control técnico de la educación. Esta entrega de libros se realizó sin políticas de lectura que las acompañaran. Simplemente, las cajas llegaban a las escuelas y su circulación quedaba a cargo de la gestión institucional.

A partir del año 2004, el Programa Global de Adquisición de Libros (2004-2006) fue gestionado por el Programa Integral para la Igualdad Educativa (PIIE) y el Programa Nacional de Bibliotecas Escolares. En el caso de PIIE se distribuyó la "Biblioteca PIIE", con una cuidadosa selección de cuatrocientos cincuenta títulos entre los que se incluían una importante cantidad de literatura infantil y juvenil, algunos destinados a la formación del docente como adulto lector (una de las líneas de trabajo del Plan de Lectura dirigido por Gustavo Bombini entre 2003 y 2008) y otros destinados a la problematización sobre lectura y lectores. La selección se realizó articulada con el Plan Nacional de Lectura desa- 
rrollado en ese momento en el Ministerio de Educación de la Nación y estuvo a cargo de técnicos ministeriales, entre los que se destacan Gustavo Bombini y Alicia Salvi, ambos referentes del campo de la LIJ.

En 2010, la tarea de selección y distribución de bibliotecas escolares quedó a cargo de la Dirección Nacional de Políticas Socieducativas, a través de la conformación de Comisiones Asesoras Nacionales (en adelante, CAN). Esta operatoria contempló la adquisición en el mercado editorial de libros de texto, literarios y de consulta, a partir de una elección realizada por comisiones de expertos. La inversión de 400 millones de pesos destinada al "Operativo Nacional de Entrega de Textos y Libros Escolares” para las escuelas públicas previó la distribución de más de 13 millones de libros, concretada básicamente entre 2013 y 2015. La intervención del Estado en la compra de libros desde 2003 (54 millones de libros) impactó fuertemente en la industria editorial del país. Incluso, desde el año 2002, se ha reconocido un régimen legal especial -Ley de Defensa de la Actividad Librera- para las adquisiciones del Ministerio de Educación, ministerios de educación provinciales y la Comisión Nacional de Bibliotecas Populares, generando descuentos de hasta el 50\% sobre el precio de tapa, para compras oficiales (Toledo et al, 2014). La investigación realizada sobre planes de lectura desarrollados en el país entre 2004 y 2010 (Bustamante et al, 2012) nos ha permitido recoger información sobre el volumen de libros adquiridos también por las provincias, para acciones focalizadas desde sus ministerios de educación.

La distribución de colecciones consolidadas por las CAN sufrió diferentes vaivenes causados por el estado deliberativo registrado en etapas electorales, así como por los resultados de las elecciones nacionales. Esto ocasionó que aún en 2019 se encontraran, en distintos depósitos provinciales, cajas de la Colección Literaria para los diferentes niveles educativos, sin entregar. Por ello nos interesa estudiar esta operatoria para reflexionar acerca del posible impacto que estas políticas educativas podrían tener en el campo curricular para la enseñanza de la literatura, en tanto en los procesos de constitución del canon literario escolar se entrecruzan prescripciones curriculares, decisiones profesionales y personales de los docentes y la disponibilidad material de los textos, como "canon disponible" (Fowler, 1988; Bombini, 1996; Piacenza, 2001)

En diferentes artículos hemos sostenido que las políticas de provisión de los Estados (nacional y provinciales), estarían garantizando cierta disponibilidad material de los textos literarios. Nótese el potencial, en tanto la noción de disponibilidad material de los libros de literatura debe relativizarse en línea con la disponibilidad simbólica, a través de la cual los sujetos se sientan habilitados e interpelados para su apropiación. Resultan centrales aquí los conceptos de Judith Kalman (2004) respecto de que la desigual distribución de la lengua escrita está siempre vinculada con cuestiones de poder que influyen tanto en su disponibilidad como en su apropiación. En este sentido, entendemos que -aunque no sea el objetivo de esta presentación- junto a las políticas de dotación de libros es imprescindible estudiar las de formación inicial y continua del docente como lector y como mediador de lectura ${ }^{3}$.

En efecto, nuestros estudios sobre impactos de las políticas públicas de lectura en la provincia de Salta (Bustamante et al, 2012) nos ponen frente al hecho de que la existencia material de los libros no conlleva necesariamente su circulación y/o la habilitación en términos simbólicos para que los sujetos se apropien de su lectura. Inciden en ello la propia 
biografía lectora de los docentes, la educación literaria recibida no sólo en su trayectoria escolar sino también en su formación docente, su formación teórica y estratégica como mediador de lectura, entre otras cuestiones. Por esto, resultan por lo menos polémicas las decisiones de entrega de libros sin el acompañamiento de políticas de lectura que entiendan a ésta como práctica sociocultural y de políticas de formación docente continua que acompañen las decisiones didácticas en torno de las bibliotecas recibidas. Sin embargo, es evidente la importancia que tienen las entregas de libros -en el formato de bibliotecas/ colecciones escolares, organizadas con cierta lógica de corpus- para la vida de las instituciones educativas. Por ello, resulta fundamental para la investigación analizar las colecciones distribuidas en relación con su circulación y los posibles efectos de estos corpus en la constitución del canon escolar durante los próximos años.

La lectura de las "Bases para la selección de colecciones literarias destinadas a adolescentes y jóvenes que concurren a la educación secundaria” publicadas en la página oficial del Ministerio de Educación en el año 2010 da cuenta de un interesante proceso: al tiempo que se realizaba una convocatoria abierta a la industria editorial del país para presentar los títulos que ofrecerían para las compras estatales, se constituía una CAN -conformada por representantes de las distintas provincias- para la lectura y selección de los textos y armado de las colecciones. Cada provincia escogía especialistas en Literatura infantil y juvenil (en adelante, LIJ), formación de lectores, docentes en ejercicio, gestores culturales y/o funcionarios educativos, etc. que debían llenar una declaración jurada con sus currículos vitae, de modo de poner a disposición de las editoriales las diversas trayectorias y transparentar -para su impugnación- las posibles relaciones y/o intereses comerciales con algunas de estas empresas. Con ello, se amplió la gestión de las políticas públicas en tanto los encargados de la selección provenían de formaciones y sectores diversos y no se trató solamente de funcionarios educativos centrales y/o de asesores procedentes de la academia.

Si bien el análisis de las "Bases" antes citadas da cuenta de cierta labilidad en el criterio de tipologización -en el que se entremezclan clasificaciones genéricas (narrativa, teatro, poesía) con cuestiones temáticas ("viajes, humor, misterio"...), otras provenientes de los recortes de las literaturas nacionales ("teatro argentino, latinoamericano", etc. ) y/o con los enfoques historiográficos (por ejemplo, "literatura siglo XX")- interesa resaltar la innegable voluntad de la convocatoria para ampliar el canon de lecturas que se pondrían en circulación en el mundo escolar desde la política de dotación del Estado.

La amplitud de la convocatoria -editoriales, géneros y subgéneros- generó gran volumen y diversidad de títulos y autores para elegir. Las entrevistas en profundidad realizadas a representantes de distintas provincias recogen relatos similares respecto de la cantidad de cajas y mesones de libros que debían revisarse en el transcurso de semanas de encuentros federales. Las narrativas recogidas relatan los viajes a Buenos Aires de los equipos provinciales solventados por el Ministerio de Educación de la Nación, la concentración en lugares específicos, la conformación de mesas de trabajo para la lectura y selección de los títulos propuestos por las editoriales, las horas de lectura individual y grupal así como las extenuantes discusiones en torno de cada uno de ellos y las diferentes rondas de selección realizadas hasta lograr consolidar la colección para cada nivel educativo ${ }^{4}$.

Las personas entrevistadas dan cuenta de cómo fueron variando -desde la primera convocatoria hasta las últimas- los criterios con que las editoriales presentaban los títulos a 
licitar y coinciden en señalar que desde la CAN se enviaron claras señales a la industria respecto de lo que se consideraba necesario y de calidad aceptable para el mundo educativo. Entre los documentos recogidos, encontramos distintas grillas y actas firmadas por integrantes de las CAN que muestran los diversos procesos de selección llevados a cabo hasta llegar a la "Colección de obras literarias de nivel secundario" consolidada, cuya diversidad es correlativa con la amplitud de las convocatorias descriptas hasta aquí.

En esta oportunidad nos abocaremos a realizar un paneo descriptivo/analítico sobre los títulos y autores del recorte "literatura infantil y juvenil" existentes en la colección, especulando acerca de su inserción en el estudio del sistema literario y sus posibles diálogos con la educación literaria y el canon literario escolar.

\section{Colección consolidada: entradas posibles a la Colección Literaria para Secundaria}

La diversidad de la convocatoria a editoriales y especialistas descripta se tradujo en una colección escolar que incorpora no sólo textos narrativos, sino también muchos de teatro, poesía, novelas gráficas, historietas y libros álbum ${ }^{5}$. En el acta de consolidación que acompaña el listado de libros seleccionados, los especialistas afirman sus criterios de elección:

- Por el espesor de las palabras y las estrategias discursivas que despliegan, permitan acceder a mundos posibles, multiplicidad de sentidos, lecturas y apropiaciones diversas.

- Por las temáticas que abordan y las prácticas que inscriben, interpelan a los lectores, permitiéndoles interrogarse sobre la condición y la experiencia humana en sus múltiples dimensiones.

- Permiten el diálogo con las prácticas culturales de las diversas infancias y juventudes que recorren nuestro país a lo largo y a lo ancho de su geografía. Asimismo, se articulan -en términos de tradición y ruptura- con el sistema literario y cultural en su conjunto.

- Ofrecen distintos accesos materiales y simbólicos a la lectura para diferentes sectores sociales y generacionales.

- No sólo funcionan en el aula, sino que la trascienden y contribuyen a la construcción de ciudadanía crítica y activa.

- Colaboran -en el caso del ciclo básico- en la articulación con el nivel primario, a partir de una variedad que propicie la formación de lectores y atienda a preferencias diversas.

- Además del trabajo con el lenguaje, tuvieran especial cuidado en la edición y en la calidad de la ilustración, en tanto potencial constructora de sentidos.

- De acuerdo con los pliegos de la convocatoria y el volumen de las presentaciones editoriales, revelen un equilibrio entre los géneros y los subgéneros seleccionados. (sic. Acta de consolidación de colección, CAN de obras literarias, 2011).

Puede inferirse el objetivo de sostener/fortalecer en las bibliotecas escolares el canon literario escolar en tanto se incluyen en la Colección títulos y autores altamente canónicos para la escuela secundaria argentina, como Martín Fierro, (aunque en la versión ilustrada 
por Fontanarrosa) o El matadero junto a otros provenientes de circuitos no canónicos, como la literatura juvenil o la novela gráfica.

Para el estudio de la colección destinada al nivel secundario, recuperamos nociones de Silvia Barei (1993) sobre el campo cultural, metaforizado como una gran esponja, cuya estructura profundamente conectada -hacia dentro y hacia afuera- presenta un diseño en constante movimiento. La autora pone en cuestión la aplicación de la noción de "campo" propuesta por Pierre Bourdieu a lo cultural y señala su estrechez frente a la complejidad laberíntica del campo cultural. Indica, además, la presencia de textos de difícil clasificación, por lo cual es necesario reconocer la pluralidad de accesos. Se trata de entender lo cultural como un sistema multicentrado, propone Barei, en el que no habría unidades jerárquicas superiores sino relaciones transversales o de lateralización. (Barei, 1993, p. 12) Nos interesan los conceptos expuestos en tanto entendemos que pueden permitir ampliar la mirada sobre la discusión literatura infantil y/o juvenil versus literatura y toda la problematización acerca de la primera. En efecto, si entendemos el campo cultural como poblado de galaxias textuales podríamos reconocer fuerzas gravitacionales (definidas por Barei como aquellas que tienden a atraer a todos los textos entre sí) y fuerzas nucleares que liberan energías. Así, sería posible reconocer efectos de intertextualidad, de oposición y anulación, de redundancia, de discontinuidad entre los textos específicamente producidos para niños y jóvenes, los recibidos y/o apropiados por éstos (tanto en el circuito escolar como a través de redes sociales), aunque su instancia de producción fuera otra y los producidos sin considerar este receptor empírico en particular. Esta mirada nos permite recuperar herramientas de lectura para reconocer modos de codificación similares o diferentes, relaciones entre textos, pasajes, espacios de convergencia o discontinuidad, etc. Esta perspectiva nos interpela -frente a cada texto puesto en circulación en el recorte Literatura infantil y juvenil- en el sentido de preguntarnos cuál es su capacidad de trastorno de equilibrio del centro y sus interrelaciones. Es más, podríamos preguntarnos cuál es el supuesto "centro" desde el que se lee la Literatura infantil y juvenil o se la descalifica, en algunos casos, o cuáles son las relaciones literatura-industria cultural desde este posicionamiento.

En este sentido, un criterio posible de selección (tema que nos desvela, sobre todo a los docentes y adultos encargados de selecciones de literatura para la infancia o la juventud) y de mediación de lectura con los jóvenes giraría en torno de reconocer modos de codificación similares o diferentes, relaciones entre textos, pasajes, espacios de convergencia o discontinuidad, etc. en el campo cultural. De esta manera, más allá de una etiqueta editorial que nos indique que un texto estaría "destinado" para determinada edad, podríamos intentar entender la importancia que revisten -para toda la actividad cultural- las condiciones de producción de los textos y la construcción de la intersubjetividad en el sentido bajtiniano de contenido ideológico de la conciencia, esa bisagra situada entre lo individual y lo colectivo. Es desde estas nociones que proponemos distintas entradas a la Colección estudiada, poniendo el foco en títulos puestos en circulación por la industria editorial como literatura juvenil. 


\section{Entrada 1: Sagas y fantástica en la literatura juvenil}

Desde el punto de vista de las fuerzas gravitacionales (Barei, 1993) -entendidas como aquellas que tienden a atraer a los textos entre sí- encontramos en la Colección de secundaria, títulos como La saga de los confines de Liliana Bodoc, Dragón (Gustavo Roldán) y Las mil y una noches argentinas (Draghi Lucero) Éstos dan cuenta de fluidos diálogos con la tradición literaria del fantasy en tanto existencia de mundos paralelos, con diversas cualidades oníricas junto a una serie de datos que subvierten el género, en el sentido propuesto por Jackson (1986). Dedicaremos especial atención al caso de La saga de los confines, en la que el traslado de los escenarios lejanos -típicos de la épica fantástica- al escenario americano, junto a la densidad poética de Bodoc constituyen dos de las apuestas más fuertes de esta selección. Resulta fundamental señalar que la biblioteca incluye los tres tomos de la saga. Con ello se favorece la oportunidad de emprender -en las escuelas-itinerarios completos de lectura de literatura fantástica al tiempo que se confía en lectores dispuestos a recorrer mundos complejos, con extensas genealogías y escenarios diversos como los que ofrecen las sagas en general y la de Liliana Bodoc en particular.

Focalizamos este parágrafo en la literatura fantástica en tanto, como afirma José Luis Guarner:

Es obvio que a través de lo fantástico el hombre ha querido siempre liberarse de muchas de sus obsesiones: lo fantástico ha de constituir, el día de mañana, un documento inapreciable acerca de nuestros miedos, ambiciones y nuestras esperanzas de hoy (Guarner, 1969, p. 9).

Según diversos teóricos, la moderna literatura fantástica es una reacción a la sociedad industrial y sus presiones. Afirman que no es casualidad que este tipo de literatura haya surgido en la Inglaterra del siglo XIX, el país que primero experimentó la presión de la industrialización. De hecho, algunos de sus principales representantes, como C.S. Lewis y J.R.R. Tolkien tenían una mirada crítica sobre su época.

En líneas generales, es posible definir lo fantástico desde la confrontación de dos planos (natural-conocido/sobrenatural-desconocido) que produce el quiebre de la lógica universal y provoca la duda o inquietud en el protagonista y, en un segundo plano, en el lector. De ahí que se juegue con la vacilación del lector hasta el final, con el concepto de ambigüedad. Se produce la intromisión del elemento sobrenatural o extraño en el marco empírico, real, cotidiano, conocido y minuciosamente descripto. El efecto de incertidumbre ante ese hecho produciría lo fantástico, cuando la lógica universal se quiebra ante lo increíble. Pero, además, en la literatura fantástica, el fenómeno sorpresivo dejará de serlo, de manera que se acomode a la realidad cotidiana.

La primera constatación que es posible realizar al examinar la oferta de textos de literatura juvenil en este momento, tiene que ver con el predominio de una literatura eminentemente fantástica en la literatura juvenil aparecida desde finales de los años 70. Podemos reconocer, en la base de este predominio, un buen ejemplo de las tensiones provocadas por la tendencia de otras épocas a priorizar lo didáctico-moralizante como una de las funciones centrales de la producción literaria destinada a niños y adolescentes. El auge de 
la fantástica en el recorte LIJ estaría dando cuenta de la mirada puesta sobre la función literaria antes que sobre la función educativa.

Dentro de la literatura fantástica, reconocemos el fenómeno de las "sagas" como uno de los centrales en el mundo de la literatura escrita para niños y jóvenes. De hecho, el campo editorial ha encontrado en las sagas fantásticas una vertiente comercial casi inagotable en su edición en los últimos años. Por ello, resulta tan importante, para los adultos mediadores de lectura, poder analizarlas críticamente.

Una saga fantástica se caracteriza por:

- Épica o ficción especulativa, basada en la creación de mundos imaginarios o universos paralelos (heterocósmica)

- Sincretismo: mezcla de géneros, motivos o mitologías previas (palimpsesto)

- Lo heroico es un principio mítico que escenifica una de las operaciones constitutivas de toda cultura.

- Un mundo ficcional apoyado sobre un esquema topológico

Una vertiente de las sagas fantásticas la constituyen las sagas dedicadas a la "épica fantástica”. Definida como un subgénero dentro de la literatura fantástica, la épica fantástica se caracteriza por la presencia de seres mitológicos, un fuerte componente mágico y la presencia de un héroe que representa al colectivo humano y encarna la lucha entre el bien y el mal. Reconocemos, además, la existencia de universos paralelos, con una geografía propia muy detallada y en la que aparecen seres fantásticos que suelen provenir de la tradición popular (dragones, animales parlantes, enanos, duendes, lulús, etc.). El relato transcurre un tiempo que no se corresponde con el tiempo histórico humano y es común que se trate de un cronotopo medievalizado (economía agraria, caballeros, bosques, reyes, princesas). En general, se narra el proceso de maduración de un héroe y la historia tiene una estructura de viaje en el que se recorren diferentes paisajes fantásticos.

De hecho, este nivel de complejidad y detalle con que se construye el mundo de las sagas es uno de los mayores desafíos para los lectores y el mecanismo que, de algún modo, los "fideliza". Pensemos, por ejemplo, en la ansiedad y pasión con que se espera un nuevo tomo de una saga, en los encuentros de lectores que se caracterizan como sus personajes favoritos en una práctica que resignifica las comunidades de lectura en el campo cultural, en las traducciones simultáneas que se producen, etc.

La literatura argentina tiene una vasta tradición en la fantástica. Liliana Bodoc, autora de la Saga de los Confines incluida en la Colección que estudiamos, retoma esta tradición junto a la de origen americano y europeo y la reescribe de modo magistral. Es interesante reconocer el periplo realizado por la obra de Bodoc. Editada, puesta en circulación y premiada en el recorte "literatura juvenil", produjo una serie de trastornos en el centro de este mismo recorte, obligándonos a problematizar caracterizaciones genéricas, en tanto pasó de la etiqueta editorial "literatura juvenil" a "literatura argentina", según los datos de copyrigth relevados en las distintas ediciones.

Desde la perspectiva de las fuerzas gravitacionales de las que habla Barei, podemos leer la saga de Bodoc entramada con la tradición literaria de la fantástica en el país que ha dado autores como Holmberg, Quiroga, Macedonio, Borges, Bioy Casares, Ocampo y Cortázar ${ }^{6}$. 
Por otra parte, reconocemos cómo la saga de Bodoc se entronca no sólo con la épica fantástica que en literatura tiene a El señor de los anillos como referente inmediato, sino con el conjunto del campo cultural, a través de lo que podríamos llamar la "fantástica corporativa" en relación con una serie de industrias culturales, que, en el caso de la cinematográfica y la editorial puso en circulación y reposicionó Las crónicas de Narnia y La materia oscura, entre otras.

¿Cuál es, entonces, la ruptura que leemos en la saga de Bodoc frente a la épica fantástica? Una de las primeras respuestas para esta pregunta nos la proporciona la misma autora: "La escritura de la saga de Los Confines comenzó siendo puro deseo de leer un relato épico y fantástico que hablara parecido a nosotros y tuviera nuestro color de piel", afirma (Arrizábal et al, 2001). Es desde este deseo e impulso primigenio que La saga de los confines levanta su "otra voz" y se presenta en el campo editorial de la literatura juvenil como un texto liberador de fuerzas nucleares en tanto mueve el centro de la literatura fantástica que se venía editando en el país, destinada a jóvenes.

Sabemos que la vida de los géneros literarios está estrechamente ligada a las condiciones de producción y circulación de los textos. Según Pampa Arán (1999), "la crítica especializada ha sido desplazada de los márgenes y en su lugar intervienen las lógicas del mercado y de lo públicos lectores..." (p. 95). En este sentido, resulta interesante entender el proceso seguido por la saga de Bodoc editada inicialmente como literatura juvenil y con premios nacionales e internacionales en este recorte y que fue paulatinamente moviéndose hacia otras zonas del campo literario, hasta posicionarse entre los intereses de la crítica especializada y de los investigadores en literatura argentina. Este mismo proceso nos lleva a afirmar su cualidad "subversiva" -en el sentido propuesto por Jackson (1986) - no sólo de las fronteras literatura juvenil/ literatura argentina sino también en tanto la ubicación en la topografía americana subvierte la lógica de la literatura fantástica editada hasta el año 2000 en colecciones destinadas a jóvenes, en la que predominaban los escenarios exóticos y lejanos.

Además, la saga de Bodoc inscribe una serie de discursos sociales de resistencia y oposición al de la conquista, recuperando para las tierras americanas la posibilidad de un discurso heroico desde la voz y la representación de los pueblos americanos como colectivo social. Encontramos aquí otro rasgo de "ruptura" frente a la tradición de la épica fantástica en relación con la construcción de un héroe que ya no es individual, sino colectivo y cuya lucha por el Bien (otra característica de la épica clásica) es la lucha por el poder que otorga el conocimiento nacido de sus propias raíces e identidad.

Preguntándonos por las fuerzas nucleares -en tanto liberación de energías- que la saga de Bodoc ha generado, estudiamos la aparición otras sagas, como la El último reino de Leo Batic, integrante de "La cofradía del fantasy argentino". La cofradía en su conjunto resulta un dato a considerar desde la perspectiva de fuerzas gravitacionales que nos permitirían leer prácticas narrativas que traspasan las fronteras de lo literario y funcionan en diversos zonas de la cultura a través de otros lenguajes como el cine, el cómic, los video juegos y de diversos modos de circulación, como internet. En el caso de "La cofradía del fantasy argentino", su "presentación en sociedad" se produjo a través de la red Facebook, y tanto la enunciación lingüística como el diseño visual del espacio dan cuenta de esta multimedialidad de los lenguajes. 
La lógica del mercado se mueve nuevamente a partir de la decisión de este grupo de autores que - independientemente de las editoriales en las que publican, se agrupan en esta cofradía y se presentan en sociedad desde una estética que liga con diversas prácticas: la literatura fantástica, la escritura autobiográfica en las redes sociales, el cómic, la mitología argentina, el cine y los videojuegos.

Nos resulta evidente que la saga contemporánea es un género narrativo cuya singularidad radica en el modo organizativo y el nivel de complejidad con que se representan los elementos del género fantástico en diálogo con otros discursos sociales. En este sentido, se imbrica profundamente con el campo cultural. Según Molina Ahumada “... la saga contemporánea deriva del estado de tensión imaginaria de una cultura en un momento determinado" (Arrizabal et al, 2011, p. 43) En este sentido, señalamos en la saga de Bodoc incluida en la Colección estudiada, un movimiento de recolocación de los elementos tradicionales del género fantástico, escenarios lejanos y exóticos, trasladando -al estilo de Oesterheld- el domicilio de la aventura no sólo a escenarios conocidos y cotidianos sino, básicamente, en profundo diálogo con nuestros arquetipos y prácticas culturales. Personajes complejos y precisión topográfica caracterizan a esta saga reubicando al héroe mítico en escenarios devenidos mundos complejos, donde se entrecruzan numerosas relaciones geográficas, sociales, políticas, económicas, etc.

Según Leunda (Arrizábal et al, 2011), leer en clave de saga nos implica, reconocer, no sólo un principio de ordenamiento para los diversos relatos que en ella se entrecruzan sino también la densidad de las relaciones entre los elementos culturales que en ellas se inscriben. La saga es un nodo donde la cultura cruza múltiples registros discursivos, es un género que se inserta en la maquinaria de funcionamiento cultural: estiliza voces sociales, recupera distintos lenguajes de la cultura, afirma la autora. En el caso que nos ocupa, la historia de la conquista de América se entrecruza con la presentación de prácticas sociales y sujetos culturales "otros" en relación con la tradición del fantasy literario pero profundamente nuestros en tanto parte de los procesos de identidad social y de memoria colectiva. Ubicada inicialmente en el recorte "literatura juvenil", Bodoc propone a los lectores no sólo a una profunda reflexión acerca de la sociedad argentina y latinoamericana sino, una aguda interpelación al deseo y a la resistencia ante toda forma de autoritarismo y exclusión. Dado que el fantasy (Jackson, 1986), característicamente, intenta compensar una falta resultante de constricciones culturales y es una literatura del deseo, que busca aquello que se experimenta como ausencia y pérdida, será interesante, en investigaciones específicas sobre la circulación de la Colección en las escuelas, estudiar la recepción de la saga por parte de lectores jóvenes en las aulas.

\section{Entrada 2: La memoria social en la Colección Literaria para Secundario}

Formar jóvenes lectores de literatura implica un gesto por medio del cual los adultos damos la bienvenida a los recién llegados y los acompañamos a hacerse un sitio en la plaza pública de la humanidad. La literatura que seleccionamos, los textos que les proponemos leer constituyen desafíos de distinta índole y los invitan a construir su subjetividad en el 
marco de la sociedad en que viven. Por ello, leer con jóvenes la literatura que ficcionaliza la historia los interpela para sentirse parte fundamental de la comunidad y hacerse cargo de su memoria. Dedicaremos esta sección a pensar cómo, en el discurso literario, se representa y reconfigura la memoria social y a explorar algunos de los títulos presentes en la colección de secundaria en esta línea.

Comencemos por preguntarnos de qué hablamos cuando nos referimos a la ficcionalización de la historia. La enunciación del tema parece contener, en sí misma una profunda contradicción, en tanto pone en íntimo diálogo dos términos aparentemente antagónicos: ficción e historia. Es decir, de algún modo, invención frente a realidad, "mentira" / "verdad". Si bien sabemos que el discurso literario es un discurso de alta densidad que condensa y re-escribe una serie de prácticas y representaciones sociales, la noción misma de "ficcionalizar la historia" parece problemática en términos teóricos. Un primer acercamiento nos dice que cuando hablamos de ficcionalizar la historia, estamos refiriéndonos a una serie de procedimientos por medio de los cuales se intenta dar forma y sostener la verosimilitud del relato literario, incluyendo en él algunos indicios de la historia social.

Para Paul Ricoeur la constatación de una cierta diferencia, si bien limitada y relativa, entre relato de ficción y relato histórico, basada en "la pretensión de verdad" de este último, no impide establecer firmemente la identidad estructural de ambos: su condición narrativa. Se trata, en principio, de dos formas diferentes de una misma exigencia de verdad, y ambas ponen en juego el carácter temporal de la experiencia humana. "El mundo desplegado por toda obra narrativa es siempre un mundo temporal [...] el tiempo se hace tiempo humano en cuanto se articula de modo narrativo" (1995, I: 41). O dicho de forma más definitiva: "entre la actividad de narrar una historia y el carácter temporal de la existencia humana existe una correlación que no es puramente accidental, sino que presenta la forma de necesidad transcultural" (1995, I, p. 117). En última instancia, la diferencia entre narración histórica y narración ficcional pertenece a la fase final de la mímesis narrativa, la que Ricoeur denomina mímesis 3, y radica en la operación de lectura. El lector es su clave. Por el contrario, en las dos primeras fases de la mímesis (en la captación de lo real o mímesis 1 y en su configuración textual por medio de una trama o mimesis 2) el historiador y el novelista operan de la misma forma básica, incluso en el caso de que el historiador no haga historia de acontecimientos. La Historia, en todo caso, y sea cual sea su modalidad, mantiene sus vínculos dentro de la esfera de la narración, única forma de preservar su propia dimensión histórica (1995, I, p. 377).

Sin una situación comunicativa especial, en que la existencia simultánea del autor y lector es más una presuposición que una presencia, no sería posible el juego y, por tanto, el despliegue de lo literario. Por eso, son los lectores quienes aceptan o no que el discurso que les dirige el autor, desde la autoridad y las valoraciones que le confiere la institución literaria, es realmente literario. El discurso ficcional es esencialmente un discurso jugado, actuado, que presupone de antemano los roles del lado del productor y del receptor. Esto quiere decir que el criterio de ficcionalidad es básicamente pragmático, se asienta en un pacto entre emisor y receptor. Leemos un texto literario que representa hechos históricos desde este pacto.

Podemos definir la ficción como un particular conjunto de procedimientos determinados y precisos para resolver un problema de necesidad estética. Evidentemente, en nuestro 
caso nos interesa cómo a través del lenguaje las ficciones se constituyen como tales y entablan pactos con los jóvenes lectores.

La construcción de la memoria social, junto a la problematización de una serie de representaciones del "otro" cultural pueden rastrearse en la Colección Literaria de Secundaria en títulos como El oscuro (Daniel Moyano) Memorias de Vladimir (Perla Suez), La casa de los conejos (Laura Alcoba), Una sombra donde sueña Camila O'Gormann (Enrique Molina), El desertor (Marcelo Eckhardt), Los que llegamos más lejos (Leopoldo Brizuela), Como si no hubiera que cruzar el mar (Cecilia Pisos) y El león rendido (Eduardo González) En la selección enunciada relevamos la coexistencia de voces del centro y de la periferia de la literatura nacional, junto a textos provenientes del recorte "literatura infantil y juvenil". La plurivocidad de lugares de pertenencia de los autores, lugares de enunciación de los relatos y de ámbitos de circulación en el sistema literario argentino permiten reconocer en la colección descripta una fuerte provocación a la educación literaria en la escuela secundaria argentina en tanto la construcción monológica del canon literario escolar en torno de la consolidación de la nacionalidad-ocurrida a través de la operación nacionalista de Ricardo Rojas- se ve interpelada por la inclusión de estos títulos en los que se inscriben voces y prácticas culturales históricamente silenciadas.

En este caso nos interesa indagar acerca de los procedimientos de ficcionalización de la historia registrados en el discurso literario escrito y/o publicado para jóvenes, en nuestro país a través del tiempo para reconocer cuáles se incorporan a la Colección examinada. En el devenir de la literatura para jóvenes que ficcionaliza la historia podemos reconocer dos momentos centrales en el país: el de la "novela histórica" y el de la "metaficción historiográfica". Definimos la "novela histórica" como aquel relato que representa las condiciones materiales de existencia, reflejando una conciencia histórica determinada. Se trata de un discurso de naturaleza híbrida, de un hiato entre ficción e historia y está íntimamente vinculado con una historiografía de tipo objetivista y documentalista, en la que predominan concepciones teleológicas y cíclicas de la historia. Para Kurt Spang (1998) la novela histórica crea ilusión de realidad, para captar la atención del lector de modo que pierda la conciencia de asistir a una representación. Pensemos, por ejemplo, en las novelas de Arturo Capdevila publicadas en la Colección Azul de la Biblioteca Billiken, en las que ya desde los títulos queda patente la concepción de que el motor de la historia es el individuo. Por ello, se acentúan aspectos personales, individuales, de figuras destacadas como ejemplares (por ejemplo, San Martín en El abuelo inmortal, Merceditas en La infanta mendocina, Florencio Balcarce en El niño poeta) Este tipo de novela está íntimamente vinculado con concepciones didáctico-moralizantes de la literatura infantil y juvenil.

Como se crea la ficción de que historia y ficción coinciden, en estos relatos abundan los recursos descriptivos y miméticos, los diálogos prolijos, las acciones que avanzan dejando la impresión de que la historia es una concatenación lineal de hechos y causas.

En el polo opuesto a la novela histórica, encontramos narraciones que podemos reconocer como "metaficción historiográfica". Descripta como una narrativa "anti-ilusionista" y vinculada con una historiografía interpretativa y narrativa que entiende que la historia es contingente, estos relatos develan el simulacro de la representación, tendiendo a la disolución de las narrativas legitimizadas. Con ello, se problematizan los conceptos de verdad y se representa a la historia como un rompecabezas en el que las diversas focalizaciones 
reconstruyen el pasado desde la subjetividad de personajes cotidianos, ajenos al centro, a veces, hasta marginales. Se tiende, así, a la disolución de las narrativas legitimizadas. Tal es el caso, por ejemplo, de Memorias de Vladimir, de Perla Suez, incluido en la Colección trabajada. El narrador protagonista, Vladimir, recorre su trayectoria desde la infancia en el siglo XIX en Rusia, cuando, niño, huye de un país desolado y llega a Argentina. Toda su identidad se pone en juego, con la vivencia del desarraigo, al crecer en medio de prácticas sociales extrañas. Sutilmente, la historia del país se atisba, en las poéticas pinceladas con las que Suez pinta el mundo que Vladimir habita. La voz narrativa es intimista y subjetiva y reconstruye la memoria social desde esta particular focalización. La pobreza, el hambre, la inmigración, el amor, todo pasa por el tamiza de la vivencia personal de Vladimir, ofreciendo a los jóvenes lectores una particular reconstrucción de la memoria social.

Por su parte, Carolina, la protagonista de Como si no hubiera que cruzar el mar, de Cecilia Pisos recorre el camino inverso al de Vladimir. Viaja de Argentina a España, en un periplo en el que la búsqueda de las raíces se entrecruza con la confusión que genera la inestabilidad en el propio país. Es este caso, la voz narradora de Carolina se mezcla con la presencia de cartas de su bisabuela (que recorrió sola el mismo camino, desde su España natal a la Argentina), formularios burocráticos, recetas de cocina y una diversidad de géneros que permiten leer una serie de prácticas de la posmodernidad. En esta línea, reconocemos en la narrativa de Pisos -a diferencia de la de Suez- una suerte de adhesión a la lógica de mercado (que impugnamos en otros artículos) que sostiene que una literatura juvenil debe tener protagonistas y lenguajes juveniles para producir una mal entendida identificación. La Colección estudiada presenta otros géneros en los que también reconocemos la reconstrucción de la memoria social. En el género teatral registramos -entre otras- la presencia de antologías que recogen las obras pertenecientes a "Teatro Abierto". Si bien no son objeto del análisis de este artículo, es interesante señalar los fenómenos vinculados con la circulación editorial, en este caso. El ciclo "Teatro abierto" constituyó un hito en la historia sociocultural de nuestro país, en tanto producción cultural "bajo vigilancia” (Giella, 1991). El movimiento cultural "Teatro Abierto" nació, se representó y desarrolló en el marco de la etapa final de la dictadura argentina y el comienzo de la democracia (1981-1985). La censura, las condiciones sociopolíticas, la existencia de "listas negras" de actores y escritores que no podían trabajar, las desapariciones, todo había cercado la actividad creativa, con lo cual, la primera búsqueda del movimiento de teatro independiente fue una toma de posición que le permitiera burlar estas condiciones y avanzar en la producción de un fenómeno artístico que, sin resignar el hecho estético, adviniera en una denuncia de la opresión social que se vivía. Su puesta en circulación en ediciones anotadas destinadas a la escuela y su inclusión en una biblioteca escolar, treinta y cinco años después del fenómeno, compone un escenario que interpela a docentes y estudiantes en el ejercicio de lectura de un género y unos textos fuertemente metafóricos e imbricados en la memoria social y cultural del país y, por lo tanto, desafían a repensar la educación literaria desde la perspectiva de la lectura como práctica social.

La inclusión de una variada selección de textos teatrales en la colección descripta permite leer otra invitación para la educación literaria en el país: la formación de un lector que vaya más allá del género narrativo como el más remanidamente transitado en el curriculum para instituirse como un lector "paragramático", al decir de Barthes (1994): 
Imaginarnos un lector total -es decir, totalmente múltiple, paragramático- tiene quizá la utilidad de permitirnos entrever lo que se podría llamar la Paradoja del lector: comúnmente se admite que leer es decodificar: letras, palabras, sentidos, estructuras, y eso es incontestable, pero acumulando decodificaciones, ya que la lectura es, por derecho, infinita, retirando el freno que es el sentido, poniendo la lectura en rueda libre (que es su vocación estructural), el lector resulta atrapado en una inversión dialéctica: finalmente, y no decodifica, sino que sobre-codifica; ya no descifra, sino que produce, amontona lenguajes, se deja atravesar por ellos infinita e incansablemente: él es esa travesía... ( 48 y 49 ).

\section{Historietas, polémicas y retroceso de políticas}

La amplitud y diversidad de la Colección impide abarcarla en los límites de un artículo, sin embargo, parece necesario hacer aunque sea una breve mención al sector de historietas. En nuestro país, la historieta ha vivido una historia de resistencia, de silencios y olvidos. Silencios y olvidos que tuvieron mucho que ver con la situación de producción de un género con frecuencia circunscripto a sectores de cierto poder adquisitivo. Nacida como un género de consumo popular y mirada por la crítica especializada y la escuela como un género menor, la historieta se constituyó como un discurso "otro" y desde los márgenes tensionó el canon escolar. El consumo masivo de los inicios se vio afectado históricamente por diferentes factores económicos que dificultaron la producción y la edición en nuestro país, lo que ocasionó en muchos casos el exilio de los creadores y el repliegue de los lectores. Introducir títulos como MortCinder (Oherterheld-Breccia), La mano del muerto (Lalia), Perramus (Breccia- Saturain), Reunión (Cortázar- Breccia) o Los ojos de la pantera y otras pesadillas (Lalia) en una colección literaria destinada al secundario del país implica un esfuerzo por restituir el acceso de todos los sectores socioeconómicos a un importante capital simbólico de nuestra historia cultural. Sin embargo, fue éste el sector de la colección que más debate público originó. En agosto de 2013, en vísperas de las elecciones primarias en el país, el diario La Nación titulaba "Los libros eróticos que el Ministerio de Educación mandó a las escuelas de Mendoza". Aduciendo hacerse eco de las voces de docentes, directivos, preceptores y bibliotecarios, el periódico y otros medios masivos levantaron -durante varios días- una serie de notas en las que calificaban de pornográficos libros como El inspector Justo, de Sanyú; Sin novedad en el frente, de Patricia Breccia y Polenta con pajaritos, de El Tomi. Las notas dieron lugar a un interesante estado de debate entre la docencia de todo el país y puede, aún hoy, rastrearse en foros y redes sociales. En las intervenciones, en general, pueden leerse dos posiciones fuertemente enfrentadas. Una vinculada con cierta representación idealizada de lo literario, como transmisor de valores y otra que postula la hibridez de géneros y los discursos de resistencia como criterio de selección de textos a ser leídos con jóvenes. De todos modos, la resistencia ante los títulos cuestionados fue tan tenaz que -desde la misma administración central- se decidió retirarlos y armar una colección denominada "De eso no se habla", acompañada de una cartilla de presentación y reseña de cada uno de los libros. 
Frente al escándalo generado (recolección de firmas por parte de comunidades religiosas, debates docentes y de padres, objeciones de algunos ministerios provinciales, etc.) los especialistas de la CAN, encargados de la selección, afirmaron en un informe técnico presentado durante el año 2013:

Seleccionar historietas para una biblioteca distribuida por el Estado Nacional implica ofrecer una oportunidad de diálogo entre las denominadas cultura letrada y cultura popular, entre los conocimientos y experiencias del mundo de las diversas juventudes que recorren nuestro país a lo largo y a lo ancho de su geografía y sus padres, docentes y compañeros de ruta. Creemos firmemente que es la escuela el ámbito más democrático y convocante para que los temas considerados escabrosos, perturbadores, inquietantes se traten, se elaboren, se debatan y, por esto, sostenemos que es en ella donde todas las manifestaciones culturales deben entrar, sin censuras, temores ni ambigüedades. Reivindicamos, pues, el papel del Estado que garantiza el derecho de todos y todas al acceso y circulación de los textos. Quedará en la conciencia y profesionalidad de cada docente, bibliotecario, directivo y otros mediadores acompañar, hacerse cargo y discutir sobre los libros entregados, sus temas, sus denuncias sociales en pos de la construcción de una ciudadanía crítica y responsable (Carta a Alejandro Garay, firmada por integrantes de la Comisión Asesora Nacional para la selección de obras literarias).

Sin embargo, la defensa de los especialistas de todo el país no alcanzó para preservar los libros citados en la colección. La investigación realizada nos ha permitido encontrarnos con las cajas completas de la colección "De eso no se habla" en distintos depósitos del país. La opinión pública manipulada por los medios masivos de comunicación en etapas preelectorales hizo dar marcha atrás, en este caso, a una política de dotación de libros para las escuelas.

\section{Algunas reflexiones}

El pantallazo realizado nos permite conjeturar que si las colecciones circulan adecuadamente, durante los años por venir puede producirse una importante reversión del canon literario escolar en la secundaria argentina. Es de desear que las políticas públicas de lectura presentes y futuras entramen con las aquí estudiadas, de modo de corregirlas, fortalecerlas, profundizarlas como una fuerte apuesta a la construcción de un sistema educativo que -estudiando lúcidamente su pasado- se proyecte en un porvenir más justo y democrático para todos. Sin lugar a dudas, la formación de un lector crítico de los diferentes accesos posibles a la Colección analizada constituirá un aporte en este sentido.

Si entendemos que lo más importante de una sociedad es su capacidad de producir sentidos, y que ésta se manifiesta en una diversidad de materias significantes, podemos reconocer la importancia de que textos provenientes de diferentes condiciones de producción se 
propongan -desde políticas estatales- en la escuela argentina como una alternativa para generar una "gramática de reconocimiento" (Verón, 1993) que multiplique lecturas y modos de hacerlas.

Por otro lado, si pensamos que los títulos aquí analizados circulan en el país en el recorte editorial propuesto como "literatura infantil y juvenil" (LIJ), podemos detenernos en otra potencialidad de la colección en tanto tensionante del canon escolar. Superadas miradas descalificadoras, que afirmándose en el modelo historiográfico, desconocen la LIJ, ésta ha constituido estatuto propio como campo intelectual conformado por autores, críticos, investigadores que se ocupan de ella. Entender la LIJ sólo como objeto del mercado y de las decisiones editoriales ha ocasionado la aparición de una cantidad de títulos y autores de dudosa calidad y variado oportunismo. Así, es posible encontrar una serie de "textos para..." que aún subsumen la literatura a finalidades pedagógicas, psicológicas y otras de diversa índole. Definir su existencia como campo intelectual, reposiciona a investigadores y mediadores de lectura, tanto a nivel de decisiones como de reflexiones en torno del sistema literario y de su especificidad y permite pensar en las poéticas que se conforman, en los procesos de constitución del corpus y en su potencialidad para formar lectores críticos y reflexivos.

De este modo, es posible leer los títulos propuestos en las colecciones analizadas desde la perspectiva de la literariedad de los textos seleccionados y los diálogos y polémicas que entablan con diferentes tradiciones y estéticas. Como es lógico en la multiplicidad de sentidos que circulan en el campo cultural, la colección seleccionada y entregada como parte de una política pública no puede ser valorada de modo monolítico en estos términos, y la diversidad de trayectorias y opiniones de los selectores dio lugar a la aparición de una variedad de títulos, algunos de los cuales podrían considerarse estrictamente "de mercado". Esto también es un desafío para las decisiones institucionales y de los mediadores de lectura, que, sin el peligro de caer en operaciones de censura, pueden ejercitar saludables dispositivos de lectura y discusión acerca de la tan mentada y polémica "calidad" literaria, discurso que, no podemos olvidar, está traspasado por la constitución sociohistórica del canon y por sus diferentes instancias de legitimación. Al respecto, afirma Geneviève Patte:

...Es más positivo ayudar a los niños a situar los personajes y las obras en el marco de su época. Antes que censurar, adaptar y sobreproteger al niño evitándole lecturas que nos parecen nocivas, antes que desear mantenerlo apartado de influencias que de cualquier forma lo afectan, ¿no es mejor asegurarse de que haya en la biblioteca la posibilidad de encontrar pensamientos diversos y discutirlos a través de diferentes lecturas? Antes que sofocar los problemas, ¿no es preferible permitir que los niños los enfrenten y darles los medios para discutirlos? Si no, ¿no sería subestimar su capacidad de juicio y encerrarlos estrechamente en su propia época? (...) Parece más fructífero buscar la confrontación y la coexistencia de libros que presentan puntos de vista diferentes, incluso opuestos, en vez de una imposible neutralidad (2008, p. 132-133). 


\section{Notas}

1. Disponible en https://www.oei.es/historico/xiiicumbredec.htm

2. En los estudios realizados en bibliotecas escolares de la provincia de Salta, entre los años 2000 y 2001, encontramos aún cajas cerradas y libros enfundados en sus empaques originales. Entre ellos, constatamos, por ejemplo, títulos como La literatura para niños y jóvenes, de Marc Sorianò, junto a Silencio, niños y otros cuentos de Ema Wolf, conviviendo con El estudio de casos como método de enseñanza, de Selma Wasserman. La diversidad registrada en las cajas, producto de una inversión de fondos públicos que no se articuló con claridad con fines educativos y/o de una política pública de lectura, terminó desaprovechada y arrumbada en muchas escuelas y/o en galpones del ejército, en el caso de Salta. Sin embargo, debemos destacar que se trató de una interesante distribución de cobertura nacional, que abarcó tanto escuelas públicas como privadas.

3. Entre 2004 y 2008, el Plan Nacional de Lectura, conducido por Gustavo Bombini, propuso como una de las hipótesis centrales de trabajo la necesidad de enfatizar y recuperar el espacio de la lectura del docente, como adulto lector de literatura. Básicamente, la propuesta giraba en torno de acompañar al docente en la resignificación de su propia biografía lectora, antes de pensar en la formación de nuevos lectores. En la práctica, muchas jurisdicciones del país instalaron una línea denominada "El docente como adulto lector" y desarrollaron talleres de lectura de literatura, en horario escolar, con docentes y directivos de las instituciones educativas. En estos encuentros se ponían en circulación los títulos de literatura destinados a adultos junto a los de LIJ, existentes en las bibliotecas escolares. Tal fue el caso de Salta, por ejemplo. La articulación de Plan Nacional de Lectura con el Programa para la Igualdad Educativa fue fundamental para muchas escuelas en este sentido y permitió trabajar, en línea con los planteos de Kalman, sobre la disponibilidad y la apropiación que venimos problematizando en el artículo. Por su parte, el Plan de Lectura de Córdoba continúa hoy organizando sus acciones en línea con las nociones de disponibilidad, acceso y apropiación estudiadas por la autora.

4. Si bien en este artículo nos dedicamos a la colección destinada para nivel secundario, es importante señalar que -en la misma operatoria- también se conformaron y distribuyeron colecciones literarias para las instituciones de los niveles inicial y primario, así como colecciones de aula.

5. El listado relevado en la página oficial del Ministerio de Educación de la Nación y constatado en las cajas de libros encontradas en las escuelas investigadas presenta los siguientes títulos:

- Abanzio, Abuelo y otros: El rock argentino en cien canciones, Buenos Aires, Colihue, 2013.

- Adellach y otros: Teatro breve contemporáneo argentino II, Buenos Aires, Del Sol, 2013.

- Aguirre, Sergio: El misterio de Crantock, Buenos Aires, Kapelusz, 2013.

- Alcoba, Laura: La casa de los conejos, Buenos Aires, Edhasa, 2013.

- Allan Poe, Edgar: La caída de la Casa Usher, Buenos Aires, V \& R, 2013.

- Allan Poe, Edgar y otros: Clásicos de misterio I, Buenos Aires, Sigmar, 2013.

- Almeida, Eugenia: El colectivo, Buenos Aires, Edhasa, 2013.

- Anaya, Jean: Sobibor, Buenos Aires, Macmillan, 2013.

- Añon, Alejandra: Pasacalles, Buenos Aires, Distal, 2013. 
- Apollinaire, Guillaume, Manuel Gutiérrez Nájera y otros: Siete grandes cuentos fantásticos, Buenos Aires, Capital intelectual, 2013.

- Asimov, Isaac: Amigos robots, Buenos Aires, Vicens Vives, 2013.

- Asimov, Isaac: Yo, Robot, Buenos Aires, Edhasa, 2013.

- Asimov, Isaac, Ray Bradbury y otros: Clásicos de ciencia ficción, Sigmar, Buenos Aires, 2013.

- Averbach, Márgara: La madre de todas las aguas, Buenos Aires, SM, 2013.

- Ayala, Gauna, María Eugenia Bosco y otros: Cuentos con detectives y comisarios, Buenos Aires, Colihue, 2013.

- Bailly, Jean-Christophe: Una noche en la biblioteca, Corregidor, Buenos Aires, 2013.

- Baronzini, Andrea, Andrea Cordobes y Ricardo Sorzoni (comp.): Cuentos con espectros, sombras y vampiros, Buenos Aires, Colihue, 2013.

- Barrón, Nestor (comp.): Kallfv Mapu. Tierra azul. Antología de la poesía mapuche contemporánea, Buenos Aires, Continente, 2013.

- Batic, Leonardo: Diario 3 Litoral, Buenos Aires, Albatros, 2013.

- Benedetti, Mario: Acordes cotidianos, Buenos Aires, V \& R, 2013.

- Bianki: Candombe, Buenos Aires, Pequeño Editor, 2013.

- Boccaccio, Giovanni, Anatole France y otros: Fantasmas, compilado por Eduardo Berti, Buenos Aires, Adriana Hidalgo, 2015.

- Bodoc, Liliana: La Saga de los Confines. Los días del venado. Tomo I, Alfaguara, Buenos Aires, 2013.

- Bodoc, Liliana: La Saga de los Confines. Los días de la sombra. Tomo II, Alfaguara, Buenos Aires, 2013.

- Bodoc, Liliana: La Saga de los Confines. Los días del fuego. Tomo III, Alfaguara, Buenos Aires, 2013.

- Bordons, Paloma: La Tierra de las papas, Buenos Aires, SM, 2013.

- Bornik, Aída y otros: Teatro Abierto, Buenos Aires, Corregidor, 2013.

- Bradbury, Ray: Fahrenheit 451, Buenos Aires, de la Flor, 2013.

- Breccia, Patricia: Sin novedad en el frente, Buenos Aires, Del Sol, 2013.

- Breccia, Enrique: Che - Vida de Ernesto Guevara, Buenos Aires, Doedytores, 2013.

- Brizuela, Leopoldo: Los que llegamos más lejos, Buenos Aires, Alfaguara, 2013.

- Bruel, Christian: La historia de Julia, Buenos Aires, Calibroscopio, 2013.

- Butti, Enrique M.: El diablo mete la cola, Rosario, Homo Sapiens, 2013.

- Cachimba, Max: Humor idiota, Buenos Aires, Pequeño Editor, 2013.

- Cardenal, Ernesto: Antología poética, Rosario, Homo Sapiens, 2013.

- Carrera, Arturo: Escrito con un nictógrafo, Buenos Aires, Interzona, 2013.

- Carroll, Lewis: Alicia en el País de las Maravillas, Buenos Aires, Colihue, 2013.

- Casariego Córdoba, Martín: Por el camino de Ulectra, Buenos Aires, Aique, 2013.

- Castilla, Gabriel: Telón del cielo. Diez obras mínimas para teatro de títeres, Buenos Aires, Del Cronopio Azul, Buenos Aires, 2013.

- Castilla, Manuel J.: El gozante, Buenos Aires, Del Sol, 2013.

- Castillo, Abelardo: El candelabro de plata, Buenos Aires, Alfaguara, 2013.

- Chesterton, Gilbert K.: El escándalo del Padre Brown, Buenos Aires, Andrés Bello, 2013.

- Ciruelo: Hadas y dragones, Buenos Aires, Doedytores, 2013. 
- Colombo, Jorge: Aventuras de un porteño en tiempos de la colonia, Buenos Aires, Distal, 2013.

- Coluccio, Felix: ¡Cruz diablo!, Buenos Aires, Colihue, 2013.

- Conan Doyle, Arthur, Marcel Proust y otros: Asesinos, Buenos Aires, Adriana Hidalgo, 2013.

- Córdova, Fernando: Leyendas, mitos, cuentos y otros relatos collas, Buenos Aires, Longseller, 2013.

- Córdova, Fernando: Leyendas, mitos, cuentos y otros relatos mapuches, Buenos Aires, Longseller, 2013.

- Cortázar, Julio, Silvina Ocampo y otros: Cuentos fantásticos argentinos, Buenos Aires, Puerto De Palos, 2013.

- Cortázar, Julio: Reunión, Córdoba, de la Magnolia, 2013.

- Cossa, Roberto: La Nona, Buenos Aires, Corregidor, 2013.

- Delucchi, Silvia y Noemí Pendzik (comp.): En frasco chico, Buenos Aires, Colihue, 2013.

- Denevi, Marco: Falsificaciones, Buenos Aires, Corregidor, 2013.

- De Melo, Thiago: Los estatutos del hombre, Buenos Aires, V \& R, 2013.

- De Santis, Pablo: Rey secreto, Buenos Aires, Colihue, 2013.

- De Santis, Pablo: Rompecabezas, Buenos Aires, Colihue, 2013.

- Del Campo, Estanislao: Fausto, Buenos Aires, de la Flor, 2013.

- Diego, Gerardo: Si la palmera supiera..., Buenos Aires, Aique, 2013.

- Doumerc, Beatriz y Ayax Barnes: La línea, Buenos Aires, Del Eclipse, 2013.

- Draghi Lucero, Juan: Las mil y una noches argentinas, Buenos Aires, Colihue, 2013.

- Drennen, Olga y otros: Latinoamérica en voz, Buenos Aires, Abran Cancha, 2013.

- Echeverría, Esteban: El Matadero, Buenos Aires, V \& R, 2013.

- Eckhardt, Marcelo: El desertor, Buenos Aires, Quipu, 2013.

- Ellis, Deborah: El viaje de Parvana, Buenos Aires, Macmillan, 2013.

- Ende, Michael: La historia interminable, Buenos Aires, Alfaguara, 2013.

- Escudero, Laura: Encuentro con Flo, Buenos Aires, SM, 2013.

- Esopo: Fábulas, Buenos Aires, Atlántida, 2013.

- Ezquieta, Itziar: El cuarto prohibido, Córdoba, de la Magnolia, 2013.

- Ferro, B. y E. Torres: Historias viajeras de todos los tiempos, Buenos Aires, Lugar Editorial, 2013.

- Filloy, Juan: Gentuza, Buenos Aires, El cuenco de plata, 2013.

- Filloy, Juan: Periplo, Buenos Aires, El cuenco de plata, 2013.

- Flecha, Marco, Marisa Amado, Jorge García Pérez y otros: Latinoamérica en voz 2, Buenos Aires, Abran Cancha, 2013.

- Fleischman, Sid: La gran rata de Sumatra, Buenos Aires, Macmillan, Buenos Aires, 2013.

- Fleischman, Sid: La luna del bandido, Buenos Aires, Macmillan, 2013.

- Fogwill, Rodolfo: Runa, Buenos Aires, Interzona, 2013.

- Fondebrider, Jorge: Licantropía, Buenos Aires, Adriana Hidalgo, 2013.

- Furiasse, Mariana: Rafaela, Buenos Aires, SM, 2013.

- Galeano, Eduardo: Espejos. Una historia casi universal, Buenos Aires, Siglo XXI, 2013.

- Galeano, Eduardo: Las palabras andantes, Buenos Aires, Siglo XXI, 2013.

- Gallego García, Laura: Finis mundi, Buenos Aires, SM, 2013. 
- Gamoneda, Antonio: Lengua y herida, Buenos Aires, Colihue, 2013.

- Gandolfo, Elvio: Ómnibus, Buenos Aires, Interzona, 2013.

- García Lorca, Federico: Federico. Antología, Buenos Aires, Colihue, 2013.

- Gelman, Juan: Violin y otras cuestiones, Grupo Planeta, Buenos Aires, 2013.

- Gil López, Olga: Adiós Rapa Nui, Buenos Aires, Del Eclipse, 2013.

- Giménez, Eduardo Abel: Como agua, Buenos Aires, Del Eclipse, 2013.

- Girondo, Oliverio: Noche tótem, Buenos Aires, Del Sol, 2013.

- González, Eduardo: El león rendido, Buenos Aires, Alfaguara, 2013.

- Gorostiza, Carlos: El puente, Buenos Aires, Colihue, 2013.

- Gorostiza, Carlos: Los prójimos, Buenos Aires, Corregidor, 2013.

- Gorostiza, Carlos: Teatro 3, Buenos Aires, de la Flor, 2013.

- Hawthorne, Nathaniel y otros: Cuentos más cuentos, Buenos Aires, Letra Impresa, Buenos Aires, 2013.

- Hazas, Antonio y otros: Cervantes, Buenos Aires, Vicens Vives, 2013.

- Hernández, Felisberto: Las hortensias y otros relatos, Buenos Aires, El cuenco de plata, 2013.

- Hernández, José: Martín Fierro, Buenos Aires, de la Flor, 2013.

- Hernández, Miguel: Corazón alado, Buenos Aires, Vicens Vives, 2013.

- Hoffmann, E.T.A., Howard P. Lovecraft y otros: Siete grandes cuentos de terror, Buenos Aires, Capital Intelectual, 2013.

- Horowitz, Anthony: El horrible sueño de Harriet, Buenos Aires, Fondo De Cultura Económica, 2013.

- Iritano, Graciela (comp.): Poemas para mirar, Buenos Aires, Colihue, 2013.

- Jiménez, Reynaldo: Poesía quechua. La bárbara tristeza, Leviatán, Buenos Aires, 2013.

- Johansen, Kevin y Liniers: Oops!, Buenos Aires, de la Flor, 2013.

- Kordon, Klauss: El muro, Buenos Aires, Puerto De Palos, 2013.

- Laiseca, Alberto: Poemas chinos, Buenos Aires, De Los Cuatro Vientos, 2013.

- Laiseca, Alberto: Cuentos de terror, Buenos Aires, Interzona, 2013.

- Lalia, Horacio: La mano del muerto, Buenos Aires, Del Sol, 2013.

- Lalia, Horacio: Los ojos de la pantera, Buenos Aires, Colihue, 2013.

- Langsner, Jacobo: Esperando la carroza, Buenos Aires, Estrada, 2013.

- Landauro, Antonio: Leyendas y cuentos indígenas de Hispanoamérica, Buenos Aires, Andrés Bello, 2013.

- Le Clezio, Jean Marie: Urania, Buenos Aires, El cuenco de plata, 2013.

- Le Guin, Úrsula K.: El mundo de Rocannon, Buenos Aires, Edhasa, 2013.

- Lipcovich, Pedro: Muñecos chicos, Buenos Aires, El cuenco de plata, 2013.

- Lovecraft, Howard P.: Bestiario, Córdoba, de la Magnolia, 2013.

- Lovecraft, Howard P.: Cuentos de terror, Buenos Aires, Andrés Bello, 2013.

- Marechal, Leopoldo: Antígona Vélez, Buenos Aires, Colihue, 2013.

- Markic, Mario: Cuadernos del camino. De Tierra del Fuego al cometa Halley, Marea, Buenos Aires, 2013.

- Martínez, Guillermo: Crímenes imperceptibles, Buenos Aires, Grupo Planeta, 2013.

- Martínez Vázquez, Julián: El viaje de los argonautas, Buenos Aires, Estrada, 2013.

- Mc Loughlin: La rebelión de los sin recreo, Buenos Aires, Bonum, 2013. 
- Mercader, Martha: De amistades y encuentros, Buenos Aires, Sigmar, 2013.

- Molina, Enrique: Poemas selectos, Buenos Aires, Corregidor, 2013.

- Molina, Enrique: Una sombra donde sueña Camila O'Gorman y otros textos, Buenos Aires, Corregidor, 2013.

- Montecino Aguirre, Sonia: Lucila se llama Gabriela, Buenos Aires, Macmillan, Buenos Aires, 2013.

- Monteleone, Jorge (ed. lit.): 200 Años de Poesía, Buenos Aires, Alfaguara, 2013.

- Montero, José: La trampa y otros cuentos policiales, Buenos Aires, Sigmar, 2013.

- Montes, Graciela: Aventuras y desventuras de Casiperro, Buenos Aires, Buenos Aires, 2013.

- Moyano, Daniel: El oscuro, Buenos Aires, Del Sol, 2013.

- Ocampo, Silvina y otros: Cuentos extraños y fantásticos, Estrada, Buenos Aires, 2013.

- Orozco, Olga: Obra poética, Buenos Aires, Corregidor, 2013.

- Oski: Vera historia de Indias, Buenos Aires, Colihue, 2013.

- Oz, Amos: De repente en lo profundo del bosque, Buenos Aires, Fondo De Cultura Económica, 2013.

- Palacios, Cristian: Mundo Bilina, Buenos Aires, SM, 2013.

- Palacios More, René(comp.): Aborígenes americanos. Colibríes Encendidos, Buenos Aires, Leviatán, 2013.

- Pedroni, José: Antología Poética, Rosario, Homo Sapiens, 2013.

- Pérez, Irene (comp.): Teatro breve contemporáneo argentino III, Buenos Aires, Del Sol, 2013

- Pérez Díaz, Enrique: Miedos de invierno, Buenos Aires, Aique, 2013.

- Peyrou, Manuel: Los mejores cuentos policiales, Buenos Aires, Corregidor, 2013.

- Piglia, Ricardo: La ciudad ausente, Córdoba, de la Magnolia, 2013.

- Pinedo, Rafael: Plop, Buenos Aires, Interzona, 2013.

- Pisos, Cecilia: Como si no hubiera que cruzar el mar, Buenos Aires, Alfaguara, 2013.

- Pommaux, Yvan: Teseo. Cómo nacen las leyendas, Buenos Aires, Continente, 2013.

- Roldán, Gustavo: Dragón, Buenos Aires, Random House Mondadori, 2013.

- Rosell, Joel Franz: La leyenda de Taita Osongo, Buenos Aires, Fondo de Cultura Económica, 2013.

- Rovner, Eduardo: Teatro 1, Buenos Aires, de la Flor, 2013.

- Sacheri, Eduardo: Lo raro empezó después, Buenos Aires, Galerna, 2013.

- Saki: El contador de cuentos, Buenos Aires, Calibroscopio, 2013.

- Saki, Guy de Maupassant y otros: Clásicos de suspenso, Buenos Aires, Sigmar, 2013.

- Salinger, Jerome D.: Nueve cuentos, Buenos Aires, Edhasa, 2013.

- Sánchez de Thompson, Mariquita: Intimidad y política. Diario, cartas y recuerdos, Buenos Aires, Adriana Hidalgo, 2013.

- Santolín, Marga: Relatos de inmigrantes, Rosario, Homo Sapiens, 2013.

- Saramago, José: Poesía completa, Alfaguara, Buenos Aires, 2013.

- Sasturain, Juan: Carta al Sargento Kirk y otros poemas de ocasión, Buenos Aires, De Los Cuatro Vientos, 2013.

- Schlaen, Carlos: Ulrico, Buenos Aires, Del Eclipse, 2013.

- Serrat, Juan M. y otros: Letra y música. La poesía en la canción, Estación Mandioca, Buenos Aires, 2013. 
- Shepard y Watson: Robin Hood, Cypres, Buenos Aires, 2013.

- Shua, Ana María: Cuidado que hay trampa, Buenos Aires, Random House Mondadori, 2013.

- Shua, Ana María: Planeta miedo, Buenos Aires, Random House Mondadori, 2013.

- Stevenson, Robert L.: La Isla del tesoro, Buenos Aires, Distal, 2013.

- Stoker, Bram: Drácula, Buenos Aires, Cypres, 2013.

- Suez, Perla: Memorias de Vladimir, Buenos Aires, Alfaguara, 2013.

- Tan, Shaun: El árbol rojo, Buenos Aires, Calibroscopio, 2013

- Tulián, Aldo y Javier Villafañe: Por el camino de Don Quijote, Buenos Aires, Del Cronopio Azul, 2013.

- Twain, Mark: El diario de Adán y Eva, Buenos Aires, Longseller, 2013.

- Vaccarini, Franco: El misterio del holandés errante, Buenos Aires, Pictus, 2013.

- Valentino, Esteban: Es tan difícil volver a Ítaca, Buenos Aires, SM, 2013.

- Van Gogh, Vincent: Cartas a Theo, Buenos Aires, Adriana Hidalgo, 2013.

- Vieytes, Carlos: El Teatro Argentino 1, Buenos Aires, Troquel, 2013.

- Vieytes, Carlos: El Teatro Argentino 2, Buenos Aires, Troquel, 2013.

- Vieytes, Carlos: Cuentos y leyendas de los indios americanos, Buenos Aires, Troquel, 2013.

- Vilariño, Idea: En lo más implacable de la noche, Buenos Aires, Del Sol, 2013.

- Villafañe, Javier: Circulen caballeros, circulen, Buenos Aires, Del Cronopio Azul, 2013.

- Wells, Herbert. G.: La máquina del tiempo, Buenos Aires, Cypres, 2013.

- Wernicke, María: Uno y Otro, Buenos Aires, Calibroscopio, 2013.

- Whitman, Walt: Hojas de hierba, Buenos Aires, Longseller, 2013.

6. Algunos de ellos entregados a escuelas secundarias en colecciones específicas, como la "Biblioteca Cortázar", por ejemplo.

\section{Referencias bibliográfícas:}

Arán, P. (1999). El fantástico literario. Córdoba: Narvaja editor.

Arrizabalaga, M. I.; Leunda, A. I. y Molina, P. (2011). Bajo el cielo de la saga. Hacia una neoépica argentina. Córdoba: Facultad de Lenguas, UNC.

Barei, S. (1993). "La gran esponja: el campo cultural" en Espacios populares en la cultura. Fac. de Filosofía y Humanidades. U.N.C.

Barthes, R. (1994). El susurro del lenguaje. Más allá de la palabra y la escritura. Barcelona: Paidós.

Bombini, G. (1996). Sobre el sentido de enseñar literatura en Fuentes para la transformación curricular. Buenos Aires: MCyEN (p. 15-53).

Bourdieu, P. (2002). Campo de poder, campo intelectual. Itinerario de un concepto. Buenos Aires: Montressor.

Bustamante, P. (2006). La Biblioteca P.I.I.E.: invitación y desafío. Recuperado de https:// www.oei.es/historico/oeivirt/animalectura.htm

Bustamante, P. (2012). Conjeturas. Acerca de lectura, lectores y literatura. Buenos Aires: Ediciones El Hacedor. 
Finnegan, F. y Serulnikov, A. (2016). Políticas públicas de provisión de libros a escuelas y estudiantes. Tendencias y debates en el contexto regional. Recuperado de https://www.ar gentina.gob.ar/sites/default/files/08-florencia-finnegan-y-adriana-serulnikov-provisionde-libros-issn.pdf

Fowler, A. (1988). “Género y canon”. En Garrido Gallardo, M. A. (Ed) Teoría de los géneros literarios (pp. 95-127). Madrid: Arco.

Giella, M. A. (1991). Teatro abierto 1981. Volumen I. Buenos Aires: Corregidor.

Guarner, J. L. (1969). Antología de la literatura fantástica española. Barcelona: Bruguera.

Jackson, R. (1986). Fantasy: literatura y subversión. Buenos Aires: Ed. Catálogos.

Jitrik, N. (1995). Historia e imaginación literaria. Las posibilidades de un género. Buenos Aires: Biblos.

Kalman, J. (2004). Saber lo que es la letra. Una experiencia de lectoescritura con mujeres mixquic, México: Siglo Veintuno.

Oleza, J. (1996). "Una nueva alianza entre historia y novela. Historia y ficción en el pensamiento literario del fin de siglo”. En J. Romera, F. Gutiérrez, y M. García-Page eds. La novela histórica a finales del siglo XX (pp. 81-97). Madrid: Visor Libros.

Pattè, G. (2008). Déjenlos leer: los niños y las bibliotecas. México: FCE.

Piacenza, P. (2001). Enseñanza de la literatura y procesos de canonización en la escuela media argentina (1966-1976). En Lulú Coquette. Revista de Didáctica de la Lengua y la Literatura, año $1, \mathrm{n}^{\circ} 1$, p. 86-96.

Pons, M. C. (1996). Memorias del olvido. La novela histórica de fines del siglo XX. México: Siglo XXI.

Pulgarín, A. (1995). Metaficción historiográfica. La novela histórica en la narrativa hispánica posmodernista. Madrid: Espiral hispanoamericana.

Ricoeur, P. (1995). Tiempo y narración. Configuración del tiempo en el relato histórico. S.XXI.

Sagrillo, S. (2011). La otra voz en La saga de los confines. Un estudio sobre la trilogía de Liliana Bodoc. Mendoza: EDIUNC.

Spang, K. (1998). “Apuntes para una definición de la novela histórica”. En La novela histórica. Teoría y comentarios. Pamplona: Ediciones de la Universidad de Navarra.

Toledo, A. et al (2014). Gasto público en la educación de América Latina ¿Puede servir a los propósitos de la Declaración de París sobre los Recursos Educativos Abiertos?. Organización de las Naciones Unidas para la Educación, la Ciencia y la Cultura. Recuperado de http://www.unesco.org/new/fileadmin/MULTIMEDIA/FIELD/Montevideo/pdf/ CDCI1-Karisma-ES.pdf

Vázquez, L. (2004). "El silencio de la industria editorial argentina en la producción de revistas de historietas". En Tebeosfera. Revista electrónica de estudio de la caricatura, el humor gráfico, la historieta y medios anejos. Recuperado de http://www.tebeosfera.com/1/ Seccion/AEC/06/Revistas.htm

Verón, E. (1993). La semiosis social. Barcelona: Gedisa. 


\begin{abstract}
The article analyzes the material presence of literary plays in Argentinian schools. It checks the state responsability in the distribution of material and symbolic goods through the analysis of reading in public politics and the supply of literary collections developed during the period 2010-2015, from de Social and Educational Direction of the Ministry of Education of the Nation, and its possible effects on the school literary standards. It is inquired, particularly on the presence of authors and titles of children and adolescent's literature included in the literary libraries studied.
\end{abstract}

Keywords: Books - School Literary Standards - Argentina.

Resumo: $\mathrm{O}$ artigo analisa a presença material de obras literárias nas escolas argentinas. Revisa a responsabilidade do Estado na distribuição de bens materiais e simbólicos por meio da análise de políticas públicas de leitura e o fornecimento de coleções literárias desenvolvidas durante o período 2010-2015, da Diretoria de Políticas Socioeducativas do Ministério Nacional da Educação, e seus possíveis efeitos sobre o cânone literário escolar. Se indaga particularmente, na presença de autores e títulos recortados da literatura infantil e juvenil incluídos nas bibliotecas literárias estudadas.

Palavras chave: Livros - Cânone literário escolar - Argentina.

[Las traducciones de los abstracts fueron supervisadas por el autor de cada artículo] 